\title{
HEALTH-RELATED QUALITY OF LIFE IN DIABETIC PATIENTS
}

\section{IN SOUTHERN GAZA STRIP, PALESTINE}

\author{
Akram M. H. Altaher, Abed ElKader Y. Elottol, Osama K. Abu Masoud \\ Department of Medical Sciences, University Collage of Science and Technology-Khanyounis, Gaza \\ Strip, Palestine \\ ${ }^{*}$ Corresponding Author: a.taher@cst.ps
}

\begin{abstract}
Introduction: Diabetes mellitus is a multifactorial disease caused by deficiency in insulin secretion, insulin action, or both. Poor quality of life contributes to decreased personal care, which in turn contributes to worsening glycemia control, enhanced risk of diabetic complications. This study aimed to determine the health-related quality of life (HRQOL) for diabetics as compared to gender-age matched control living in southern Gaza, Palestine. Methods: This study was a case-control. About 100 DM patients and age-sex matched 100 controls were randomly selected from the department of internal medicine at the Nasser Medical Complex in Khanyunis Governorate and the community. The World Health Organization Quality of Life Questionnaire - short version (WHOQOL-BREF) was used to evaluate the quality of life among the study population. Results: Those with diabetics, the HRQOL was significantly lesser than for controls in all domains with the largest differences in the environmental domains (difference of 5 points) and tinier differences in physical health, psychological health \& social relationships $(2,3$ and 3 points difference) $(<0.001$ for all). Low ratings in the field of social relations in both groups with tiny differences between them have been registered ( 3 points). Furthermore, there were no differences in mean of scores for all domains according to gender. Conclusion: The study population's total HRQOL (diabetics and controls) was poor. Health program must be developed to encourage improve dietary habits, healthier lifestyle, promote exercise, discourage smoking, avoid complications of diabetes and appropriately handle chronic diseases.
\end{abstract}

Keywords: Diabetes mellitus; Health-related quality of life; WHOQOL-BREF; Palestine. 


\section{Introduction}

Diabetes mellitus (DM) is a multifactorial disorder associated with hyperglycemia in addition to carbohydrate, fat and protein metabolism disorders arising from insulin secretion deficiency, insulin action, or both (Altaher, et al., 2017). Chronic elevated blood glucose in diabetics can lead to long-term dysfunction, and multiple organs failure, including eyes, kidneys, nerves, heart, and blood vessels (Wendy and Jean, 2007). Over the past two decades, the prevalence of DM has increased significantly (Pearson, 2003). According to recent estimates; there was nearly 135 million individuals with DM around the world in 1995, and this number estimated to rise to 300 million by the year 2030 (King, et al. 1998). In 2018, there were 538 deaths due to complications of DM and these complications came in the fifth leading cause of death among Palestinian with a proportion of $7.5 \%(\mathrm{PMOH}, 2018)$. In fact, long-term diabetes complications such as retinopathy, nephropathy, neuropathy, heart disease, and stroke, with their significant health impact, may also have an adverse effect on quality of life (Redekop, et al., 2002). Quality of life is a significant element for diabetes mellitus because poor quality of life contributes to decreased personal care, which in turn contributes to worsening glycemia control, enhanced risk of diabetic complications, and overwhelming aggravation of DM both in the brief and long term (Jain, et al., 2014). It is therefore evident that quality of life topic is essential and predict how well a person can manage his illness and sustain long-term health and well-being (Jain, et al., 2014). It is also essential to assess the perceived burden of diabetic patients about his chronic disease situation, in order to observe the trends in overtime health and quantify the therapy impact (Vigneshwaran, et al., 2013). The UK Prospective Diabetes Study has demonstrated that adequate glycemic control can significantly decrease complications of DM, open the way for early diagnosis and appropriate management advantages (Davis, et al., 2001).

DM is well-recognized to be associated with enhanced morbidity and mortality. But the impact of this disease on functional state of health and well-being is not yet well recognized (Jain, et al., 2019). HRQOL is the actual difference between one's expectations and one's actual physical, emotional, and social functioning (Jain, et al., 2019). Several studies have reported that health-related quality of life (HRQOL) is affected negatively by diabetes, especially in the presence of complications (Coffey et al., 2002; Redekop, et al., 2002; Smith, 2004; Vileikyte, et al., 2005; Goodridge, et al., 2005; Eljedi, et al., 2006; Jain, et al., 2014). However, most of these studies were carried out in developed countries (Garratt, et al., 2002). Unfortunately; there were few studies have been conducted about the HRQOL in diabetic patients in developing (Aghamollaei et al., 2003; Ghanbari, et al., 2005; Savli, \& Sevinc, 2005; Aghamollaei et al., 2005). These studies ' results were diverse and distinct from one country to another owing to differences in dietary habits, lifestyle attitude, severity and disease duration among them. Therefore, the main aim of this study was to determine the HRQOL for patients with DM as compared to gender-age matched control in southern Gaza strip, Palestine. In addition, to find out the gender differences in diabetic group according to quality of life.

\section{Methods}

The design of this study was a case-control carried out in between May and July 2019, The study population were 100 DM patients and age-sex matched 100 controls without diabetes living in in Khanyunis and Rafah Governorates, southern Gaza strip. The definition of DM was based on ADA guidel ines. The range of the participants was in between 18 and 65 years. The cases group was randomly selected patients from the department of internal medicine at the Nasser Medical Complex in Khanyunis Governorate (the study frame), Palestine. The controls group were selected from the community.

Epi-Info program version $(\mathrm{Vr}) 7.2$ was used to calculate the sample size at population size $=$ $100000,95.0 \%$ confidence interval $(\mathrm{Cl}), 4.0 \%$ acceptable margin of error and $9 \%$ expected prevalence of diabetes mellitus based on previous study that carried out in Palestine, The sample size was 196 diabetic patients (AlTaher, et al., 2017). Inclusion criteria for patients were any diabetic patients with or without complications, his treatment began at 6 months or more before the research has been performed. DM patients with any other disease (any chronic disease not associated with DM) and pregnant patients at the time of the study carried out were excluded from the study. All formal letters of permission were obtained to perform the research from $\mathrm{PMOH}$. Before data gathering, consent forms were provided to define the purpose and importance of the research for all research respondents. 
Face to face questionnaires were used by research team to collect the social and demographic data (e.x. gender, level of education, type of housing, etc...) and DM associated data (e.x. DM type, its duration per years, medication for DM, etc..). The differences between co-morbidities and diabetes complications were based on the patient's medical records and were not reevaluated when the research was included. The short version of World Health Organization Quality of Life Questionnaire (WHOQOL-BREF) was used by research team to assess the quality of life among the study population (Whoqol Group, 1998). This questionnaire was created to acquire a crosscultural evaluation tool with 15 global field centers. The WHOQOL-BREF is consisting of four domains which are physical health (e.x. physical pain feeling, medical treatment need), psychological (e.x. enjoy life, concentration ability), social relationships (e.x. personal relationships) and environment (e.x. opportunity for leisure activities). The participants rated all items on a 5-point Likerttype scale. The questionnaire was translated into Arabic language. The $\mathrm{Vr} 22$ of SPSS system was used for analysis of data. Descriptive statistics, Chi-Square Test and tTest were carried out at $\mathrm{Cl} 95 \%$. P-value of less than 0.05 for the test hypothesis was considered as statistically significant.

\section{Results}

Regarding the gender, this research found that $65.0 \%$ of patients were male and $35.0 \%$ were female Vs. $59.0 \%$ of control were males and $41.0 \%$ were females (Table 1). After using of Chi-Square The differences among the study population according to age, gender, education level, marital status, house type and monthly income were not reach the statistically significant levels $(P=0.714, P=0.328, P=0.660$,
$\mathrm{P}=0.062, \mathrm{P}=0.094 \& 0.626$ respectively) (Table 1). Approximately $32.0 \%$ of patients with DM were smokers Vs. $5.0 \%$ for controls $(P=0.000)$ (Table 1).

Table 2 shows the situation of clinical characteristics of diabetics (cases) by gender. The mean $\pm S D$ of diabetes mellitus duration among the diabetic males was $8.36 \pm 5.66$ years Vs. $8.05 \pm 5.33$ for diabetic females $(\mathrm{P}=0.789)$. In addition, Most of diabetic patients $(92.0 \%)$ were T2DM $(93.8 \%$ of males Vs. $88.6 \%$ of females) (Table 2). Furthermore, about $49.0 \%$ of the total diabetic subjects were intake tablets as hypoglycemic drug. Moreover, about $44.0 \%$ of the total diabetic subjects were not suffers from any diabetic complications $(47.7 \%$ of males Vs. $37.1 \%$ of females) (Table 2).

Table 3 illustrates comparison of crude domain scores between the cases group and controls group. Among diabetics, the HRQOL was significantly lesser than for controls in all domains with the largest differences in the environmental domains (difference of 5 points) and tinier differences in physical health, psychological health \& social relationships (2, 3 and 3 points difference) ( $p=0.000$ for all) (Table 3). This implies that in a comparable manner; poor physical health, poor psychological health, deteriorating social relationships, and poor environmental circumstances affect the HRQOL of both groups. In the domain of social relationships, both groups had especially low ratings with tiny differences between them (3 points).

Table 4 displays comparison of crude domain scores between the diabetic's male group and diabetic's females group. However, the differences in crude domain scores in all domains between males and females were not reach the statistically significant level $(p>0.05$ for all domains) (Table 4). 
Table 1: Distribution of the subjects by socio-demographic characteristics

\begin{tabular}{|c|c|c|c|}
\hline \multirow[b]{2}{*}{ Variables } & \multicolumn{2}{|c|}{ Subject } & \multirow[b]{2}{*}{ P-Value } \\
\hline & $\begin{array}{c}\mathrm{DM} \\
(\mathrm{N}=100)\end{array}$ & $\begin{array}{l}\text { Control } \\
(\mathrm{N}=100)\end{array}$ & \\
\hline Age (mean $\pm S D)$ & $52.0 \pm 10.4$ & $51.5 \pm 9.9$ & 0.714 \\
\hline \multicolumn{3}{|l|}{ Gender } & \multirow{3}{*}{0.382} \\
\hline Male & $(65.0 \%)$ & $(59.0 \%)$ & \\
\hline Female & $(35.0 \%)$ & $(41.0 \%)$ & \\
\hline \multicolumn{3}{|l|}{ Education level } & \multirow{4}{*}{0.660} \\
\hline Illiterate & $(18.0 \%)$ & $(21.0 \%)$ & \\
\hline Secondary & $(43.0 \%)$ & $(46.0 \%)$ & \\
\hline Undergraduate or more & $(39.0 \%)$ & $(33.0 \%)$ & \\
\hline \multicolumn{3}{|l|}{ Marital status } & \multirow{5}{*}{0.062} \\
\hline Single & $(7.0 \%)$ & $(5.0 \%)$ & \\
\hline Married & $(77.0 \%)$ & $(88.0 \%)$ & \\
\hline Widowed & $(13.0 \%)$ & $(5.0 \%)$ & \\
\hline Divorced & $(3.0 \%)$ & $(2.0 \%)$ & \\
\hline \multicolumn{3}{|l|}{ House type } & \multirow[t]{3}{*}{0.094} \\
\hline Rented & $(37.0 \%)$ & $(26.0 \%)$ & \\
\hline Owned & $(63.0 \%)$ & $(74.0 \%)$ & \\
\hline \multicolumn{3}{|l|}{ Monthly income (NIS) } & \multirow{4}{*}{0.626} \\
\hline$<500$ & $(35.0 \%)$ & $(29.0 \%)$ & \\
\hline 500 to $<1500$ & $(45.0 \%)$ & $(51.0 \%)$ & \\
\hline$>1500$ & $(20.0 \%)$ & $(20.0 \%)$ & \\
\hline \multicolumn{3}{|l|}{ Smoking status } & \multirow{3}{*}{$<0.001^{*}$} \\
\hline Yes & $(32.0 \%)$ & $(5.0 \%)$ & \\
\hline No & $(68.0 \%)$ & $(95.0 \%)$ & \\
\hline
\end{tabular}

*Level of significance at $p<0.05$

Table 2: The clinical characteristics of diabetics by gender

\begin{tabular}{|c|c|c|c|}
\hline \multirow{2}{*}{ Variables } & \multicolumn{2}{|c|}{ Gender } & \multirow[t]{2}{*}{ P-Value } \\
\hline & Male & Female & \\
\hline Duration (mean $\pm S D$ ) & $8.36 \pm 5.66$ & $8.05 \pm 5.33$ & 0.789 \\
\hline Age (mean $\pm S D)$ & $53.18 \pm 10.9$ & $49.94 \pm 9.28$ & 0.141 \\
\hline \multicolumn{3}{|l|}{ Diabetic type } & \multirow{4}{*}{$0.047^{*}$} \\
\hline T1DM & $(6.2 \%)$ & $(2.9 \%)$ & \\
\hline T2DM & $(93.8 \%)$ & $(88.6 \%)$ & \\
\hline Gestational & $(0.0 \%)$ & $(8.5 \%)$ & \\
\hline \multicolumn{3}{|c|}{ Type of hypoglycemic drug } & \multirow{5}{*}{0.510} \\
\hline Tablet & $(53.8 \%)$ & $(40.0 \%)$ & \\
\hline Insulin & $(26.2 \%)$ & $(31.4 \%)$ & \\
\hline Both & $(9.2 \%)$ & $(17.1 \%)$ & \\
\hline Following diet & $(10.8 \%)$ & $(11.4 \%)$ & \\
\hline \multicolumn{3}{|c|}{ Diabetic complication (major one) } & \multirow{6}{*}{0.764} \\
\hline None & $(47.7 \%)$ & $(37.1 \%)$ & \\
\hline Nephropathy & $(4.6 \%)$ & $(2.9 \%)$ & \\
\hline Retinopathy & $(29.2 \%)$ & $(31.4 \%)$ & \\
\hline Neuropathy & $(9.2 \%)$ & $(14.3 \%)$ & \\
\hline Diabetic leg & $(9.2 \%)$ & $(14.3 \%)$ & \\
\hline
\end{tabular}

*Level of significance at $P<0.05$. 
Table 3: Crude domain scores of WHOQOL-Bref for DM patients as compared to controls

\begin{tabular}{|l|c|c|c|}
\hline \multicolumn{1}{|c|}{ Domain } & $\begin{array}{c}\text { DM } \\
(m e a n \pm S D)\end{array}$ & $\begin{array}{c}\text { Controls } \\
(\text { mean } \pm \text { SD })\end{array}$ & P-Value \\
\hline Physical health & $23.45 \pm 2.72$ & $25.76 \pm 1.92$ & $<\mathbf{0 0 1}^{*}$ \\
\hline Psychological & $22.37 \pm 3.75$ & $25.22 \pm 1.70$ & $<\mathbf{0 . 0 0 1}^{*}$ \\
\hline Social relationships & $10.83 \pm 2.01$ & $13.05 \pm 1.88$ & $<\mathbf{0 0 1}^{*}$ \\
\hline Environment & $30.30 \pm 6.43$ & $35.12 \pm 4.29$ & $<\mathbf{0 . 0 0 1}^{*}$ \\
\hline
\end{tabular}

${ }^{*}$ Level of significance at $p<0.05$

Table 4: Crude domain scores of WHOQOL-Bref for DM males as compared to DM females

\begin{tabular}{|l|c|c|c|}
\hline \multicolumn{1}{|c|}{ Domain } & $\begin{array}{c}\text { DM Males } \\
(\text { mean } \pm \text { SD })\end{array}$ & $\begin{array}{c}\text { DM Females } \\
(\text { mean } \pm S D)\end{array}$ & P-Value \\
\hline Physical health & $23.13 \pm 2.78$ & $24.02 \pm 2.52$ & 0.119 \\
\hline Psychological & $22.13 \pm 3.29$ & $22.80 \pm 4.51$ & 0.404 \\
\hline Social relationships & $11.10 \pm 1.96$ & $10.31 \pm 2.02$ & 0.060 \\
\hline Environment & $30.06 \pm 6.45$ & $30.74 \pm 6.46$ & 0.616 \\
\hline
\end{tabular}

*Level of significance at $p<0.05$

\section{Discussion}

This study is a comprehensive study with the large sample size aimed to estimate the HRQOL for patients with T2DM as compared to age-gender matched control in Palestine. As we found in the current study, poor physical health, poor psychological health, declining social relationships and poor environmental circumstances influencing on the HRQOL of diabetics and non-diabetic controls similarly. However, the overall HRQOL of the participants of the current research (cases group and controls group) was poor. The findings of our study were in the line with most recent studies conducted to find out the status of health-related quality of life in DM patients as compared to controls (healthy individuals) (Coffey et al., 2002; Smith, 2004; Vileikyte, et al., 2005; Goodridge, et al., 2005; Eljedi, et al., 2006; Jain, et al., 2014). Eljedi, et al. (2006) performed a survey to determine the impacts of diabetes on HRQOL in Gaza Strip refugee camps under living circumstances. A sample of 197 DM patients and 197 age and gendermatched healthy individual (controls) selected from the same camps were researched. WHOQOL-BREF which including four domains (physical health, psychological, social relations and environment) was used to assess the HRQOL. Cases and controls domain scores were compared and the effect of socioeconomic factors was assessed in both groups. The results of this research showed that all domains in DM patients were sharply decreased relative to controls, with weaker impacts in social relationships domain (52.4 vs. 71.4 at $0-100$ score points) and environmental domains (23.4 vs. 36.2 ) and greater impacts in physical health domain (36.7 vs. 75.9 ) then psychological domains (34.8 vs. 70.0 ) (Eljedi, et al., 2006). In addition, heath-related quality of life of diabetics women and older diabetics subjects ( $>50$ years of old) were sharply affected by DM as compared to diabetics male and younger age group $(<50$ years). In the younger age group ( $<50$ years); the low socioeconomic status had a large negative influence on HRQOL. (Eljedi, et al., 2006). Furthermore, another case-control study conducted in India, aimed to find out HRQOL of diabetic patients attending the medical college, particularly in the department of medicine outpatient. The study population was 70 diabetics and 70 age-gender matched healthy individuals (controls) have participated in the study. WHOQOL-BREF was used to assess the quality of life. After compared the crude domain scores between the diabetics and controls; the findings showed that the scores for both groups were poor in all areas such as physical, psychological, and environmental health. But in the field of social relationships; both diabetics and controls had incredibly low ratings. This implies that both groups are likewise affected by poor physical health, poor psychological health, bad social relationships, and poor environmental conditions (Jain, et al., 2014). In contrast, two studies have reported mean scores greater in all the domains among diabetics and controls than our findings (Bech, 2001; Aghamollaei, et al., 2003). Regarding the comparison of crude domain scores between both the diabetic male group and diabetic females group. The findings of the current study showed that there 
was no difference between the two groups in domain scores in all domains ( $p>0.05$ for all domains), and this means that diabetics male HRQOL is not better than diabetics female group. This finding is inconsistent with many recent studies (Goodridge, et al., 2005; Eljedi, et al., 2006; Jain, et al., 2014). In contrast, few studies in the literature reported a high impact of interactions between condition of disease and sex among diabetics as compared to healthy individual (controls), and these studies clarified this relationship because of the worse disease condition of female patients (Redekop, et al., 2002; Aghamollaei, et al., 2003).

\section{Conclusion \& Recommendation}

In summary, patients with diabetes residing in the southern Gaza Strip have bad HRQOL in comparison to age-sex matched healthy individuals residing under the same circumstances, However, the overall HRQOL of the population of the research (diabetics and controls) was poor. Diabetes has not an impact on the HRQOL of neither females nor males. In order to maintain a good HRQOL among diabetics living in southern Gaza strip; Health program must be developed to encourage improve dietary habits, healthier lifestyle, promote exercise, discourage smoking, prevent complications of DM, and correctly handle concurrent chronic diseases. This will aid in arriving in the awaited objective of health care of diabetics particularly in Gaza strip and generally in state of Palestine.

\section{Acknowledgements}

The authors gratefully acknowledge to the Nasser Medical Complex administration and medical staff for the facilities they have provided to conduct this study.

\section{References}

Altaher, A. M., Ghafoor, E. S. A., Amudi, W. I., \& Alderby, D. K. (2017). Comparative Identification of Bacterial Quality in liquid Soap between Nasser and European Gaza Hospitals, Khanyounis Governorate. Journal of the Arab American University, 3 (1), 54-66.

Al-Taher, A. M., Aljboor, H. S., Alshaer, S. I., \& Soboh, M. M. (2017). A Comparative Study of Coronary Risk Factors Between Urban and Rural Diabetics in Gaza Strip. Journal of the Arab American University. Volume, 3(1).

Aghamollaei, T., Eftekhar, H., Shojaeizadeh, D., Mohammad, K., Nakhjavani, M., \& Pour, F. G. (2003). Behavior, metabolic control and health-related quality of life in diabetic patients at Bandar Abbas diabetic clinic. Iranian Journal of Public Health, 54-59.

Aghamolaei, T., Eftekhar, H., Mohammad, K., Nakhjavani, M., Shojaeizadeh, D., Ghofranipour, F., \& Safa, O. (2005). Effects of a health education program on behavior, $\mathrm{HbA} 1 \mathrm{c}$ and health-related quality of life in diabetic patients. Acta Medica Iranica, 89-94.

Bech, V. N. P. (2001). The WHO quality of life (WHOQOL) questionnaire: Danish validation study. Nordic journal of psychiatry, 55(4), 229235.

Coffey J. T., Brandle, M., Zhou, H., Marriott, D., Burke, R., Tabaei, B. P., ... \& Herman, W. $H$. (2002). Valuing health-related quality of life in diabetes. Diabetes care, 25(12), 2238-2243.

Davis, T. M., Cull, C. A., \& Holman, R. R. (2001). Relationship between ethnicity and glycemic control, lipid profiles, and blood pressure during the first 9 years of type 2 diabetes: UK Prospective Diabetes Study (UKPDS 55). Diabetes care, 24(7), 1167-1174.

Eljedi, A., Mikolajczyk, R. T., Kraemer, A., \& Laaser, U. (2006). Health-related quality of life in diabetic patients and controls without diabetes in refugee camps in the Gaza strip: a cross-sectional study. BMC public health, 6(1), 268.

Garratt, A. M., Schmidt, L., \& Fitzpatrick, R. (2002). Patient-assessed health outcome measures for diabetes: a structured review. Diabetic Medicine, 19(1), 1-11.

Ghanbari, A., Yekta, Z. P., Roushan, Z. A., \& Lakeh, N. M. (2005). Assessment of factors affecting quality of life in diabetic patients in Iran. Public Health Nursing, 22(4), 311-322.

Goodridge D, Trepman E, Embil JM: HealthRelated Quality of Life in Diabetic Patients With Foot Ulcers: Literature Review. J Wound Ostomy Continence Nurs 2005, 32(6):368-377.

Jain, V., Shivkumar, S., \& Gupta, O. (2014). Health-related quality of life (hr-qol) in patients with type 2 diabetes mellitus. North American journal of medical sciences, 6(2), 96.

King, H., Aubert, R. E., \& Herman, W. H. (1998). Global burden of diabetes, 1995-2025: prevalence, numerical estimates, and projections. Diabetes care, 21(9), 1414-1431. 
Palestinian Ministry of health (PMOH) (2018). The Health Annual Report, pp 93-95. Retrieved from: https://www.site.moh.ps/index/Books/BookTyp e/2/Language/ar

Pearson, T. A. (2003). Education and income: double-edged swords in the epidemiologic transition of cardiovascular disease. Ethnicity and disease, 13(2; SUPP/2), S2-158.

Redekop, W. K., Koopmanschap, M. A., Stolk, R. P., Rutten, G. E., Wolffenbuttel, B. H., \& Niessen, L. W. (2002). Health-related quality of life and treatment satisfaction in Dutch patients with type 2 diabetes. Diabetes care, 25(3), 458-463.

Savli, H., \& Sevinc, A. (2005). The evaluation of the Turkish version of the Well-being Questionnaire (WBQ-22) in patients with Type 2 diabetes: the effects of diabetic complications. Journal of endocrinological investigation, 28(10), 683-691.
Smith, D. W. (2004). The population perspective on quality of life among Americans with diabetes. Quality of Life Research, 13(8), 1391-1400.

Vigneshwaran, E., Padmanabhareddy, Y., Devanna, N., \& Alvarez-Uria, G. (2013). Gender differences in health related quality of life of people living with HIVIAIDS in the era of highly active antiretroviral therapy. North American journal of medical sciences, 5(2), 102.

Wendy, A., Jean, B. (2007): Clinical Chemistry Text Book. A Laboratory Perspective, 1st ed. F. A. Davis Company. USA. pp 147-155.

Whoqol Group. (1998). Development of the World Health Organization WHOQOL-BREF quality of life assessment. Psychological medicine, 28(3), 551-558. 